\title{
PANiZZA, C. Nicola Chiaromonte. UNA BIOGRAFIA. ROMA: DONZELLI EDITORE, 2017, 321 P.(SERIE: ITALIANI DALL'ESILIO).
}

\author{
Luciano Aparecido dos Santos*
}

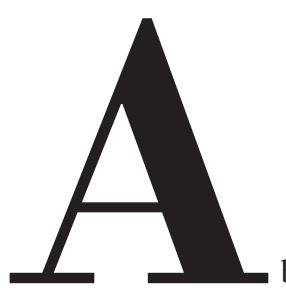

biografia de Nicola Chiaromonte, escrita pelo historiador Cesare Panizza, professor da Universidade de Torino, nos faz percorrer, em 321 páginas, a parte mais intensa dos conflitos sociais e políticos do século XX, através da vida e dos escritos de um estudioso sempre empenhado em entender o seu "Tempo Presente" correlacionado com sua existência de indivíduo.

O livro faz parte de uma série de biografias intitulada "Italiani dell'esilio", que tem como objetivo mostrar as particularidades do pensamento de escritores que passaram pela experiência de exílio durante o período fascista. Entre as biografias apresentadas nessa série estão a do sociólogo Gino Germani, a do pintor Corrado Cagli e uma compilação de cartas escritas no EUA por Gaetano Salvemini.

De fato, o livro de Panizza se mostra mais como uma biografia do desenvolvimento intelectual de um crítico, em confronto com os acontecimentos históricos nos diferentes países onde esteve, do que uma narrativa da vida de Chiaromonte. Os nove capítulos que compõem a obra se relacionam diretamente com o espaço geográfico onde se encontrava o ensaísta italiano, mostrando como o exílio foi determinante para a constituição de seu pensamento. Mesmo quando em terras italianas, Chiaromonte nunca se sentiu parte integrante daquele lugar. Os anos em Roma, marcados pela ruptura com a família e a província, ou os anos em Paris, onde não esteve propriamente exilado, também foram períodos de certo tipo de isolamento cultural. 
Além da relação de Chiaromonte com as cidades onde esteve, que nomeiam os capítulos do livro, uma outra chave de leitura são os encontros e as amizades travadas pelo escritor durante sua vida. Em cada lugar que o ensaísta esteve, existia ao menos uma figura intelectual com a qual se estreitava a troca de experiências e ideias, ampliando cada vez mais a complexidade de seu pensamento crítico e filosófico.

Os dois primeiros capítulos são dedicados è sua formação entre Roma e Rapolla ("Rapolla" - p. 9-13), cidade natal de Nicola Chiaromonte, aqui Panizza apresenta a constituição familiar e o ambiente estritamente católico no qual o crítico foi criado passando a seguir aos anos de formação na capital italiana: "Roma I. Un giovane inquieto: gli anni di formazione (19081934)" (p.15-68). Essa primeira parte da biografia é um dos pontos mais interessantes do estudo de Panizza, pois ilumina fatos até então pouco discutidos da vida do crítico italiano. Fruto de uma densa pesquisa das cartas de Chiaromonte, o autor consegue expor o ambiente no qual o jovem estudioso de direito desenvolvia sua vocação intelectual, através de figuras que foram determinantes para sua vida, como o filósofo Adriano Tilgher e Paolo Bonaiuti.

A primeira grande influência na vida intelectual de Chiaromonte foi certamente Adriano Tilgher, do qual foi amigo e uma espécie de discípulo. Tilgher foi um estudioso e crítico particular do primeiro pós-guerra. Nele, era fortíssima a intuição de que com a primeira guerra houve uma ruptura radical com o passado, com a herança do século XIX, e com ela a dissolução do mito da História como progresso ininterrupto da Razão. Chiaromonte mais tarde desenvolveria essa crítica e a levaria a diversas análises e reflexões. Essa forte intuição anti-historicista, junto com a importância dada à espiritualidade do homem, criaria no crítico uma convicção permanente em sua obra: de que todo homem tem papel central no desenvolvimento da História e capacidade latente de mudar a realidade do presente. Ensaios notórios de sua maturidade, como "Tolstoi e il paradosso della Storia", "Pasternak, fra la Natura e la Storia" e "Nota sulla civiltà e le utopie", desenvolverão com propriedade essas relações.

$\mathrm{Na}$ segunda parte do capítulo II, acompanhamos os primeiros esforços intelectuais de Chiaromonte para se estabelecer como um escritor, analisando os textos iniciais publicados nas revistas Il mondo, Solaria e Oggi. Em sua maioria, os escritos dessa época eram reflexões filosóficas, ainda pouco concatenadas, e críticas teatrais, uma paixão permanente em sua vida. Essas publicações aconteceram nos primeiros anos de 1920, em meio à ascensão do regime fascista, e são marcadas pelo esforço em conciliar seu compromisso intelectual com a verdade e as limitações temáticas que a censura impunha.

Os capítulos III ("Parigi I. Nicola Chiaromonte e Giustizia e Libertà", p. 69-120) e IV ( "Parigi II. La gang, il Fronte popolare, la Spagna, la fuga (1936-1941)", p. 121-162) são reservados a sua estadia na capital francesa, anos de fundamental importância para o empenho político que os escritos de Chiaromonte nos mostra. Panizza se concentra na relação do escritor com os imigrantes italianos que compunham o grupo "Giustizia e Libertà", e posteriormente a cisão com esse grupo devido a divergências ideológicas. Durante esse período Chiaromonte se confronta com um problema nevrálgico para o entendimento de seu trabalho intelectual: o 
confronto entre plano político e responsabilidade intelectual com a verdade.

Nos cadernos de "Giustizia e Libertà", o escritor pode compartilhar suas ideias antifascistas e discutir com críticos mais experientes sobre as causas que levaram a instalação do regime fascista na Itália. Panizza mostra como, pela primeira vez, Chiaromonte escrevia com liberdade e paixão sobre a situação presente através da leitura de textos célebres de sua juventude, publicados nesse periódico, como o ensaio "La morte si chiama Fascismo". Porém, a relação com o filósofo Andrea Caffi e com o grupo dos "novatori” despertou em Chiaromonte uma responsabilidade intelectual no modo de pensar a sociedade que substituiria a fascista. Caffi foi um pensador libertário em estrito senso, refutava qualquer tipo de sistematização, qualquer ideia fundada em postulados ou princípios únicos. Sua grande crítica era contra a visão da sociedade como um sistema lógico, na qual os indivíduos e os grupos fossem fatos materiais, organizados por um sistema único e dominante.

A ruptura com Carlo Rosselli, diretor dos cadernos de "Giustizia e Libertà", se deu pela tendência restauradora defendida por Rosselli e a postura libertária do pensamento dos jovens de "La gang", como era chamado o grupo de Caffi. Deste modo, Panizza começa a situar Chiaromonte na contracorrente, mesmo entre os antifascistas, e como o crítico se compromete integralmente com o discurso intelectual de seus escritos. A decadência moral era o principal motivo elencado por Chiaromonte como responsável pelo nascimento do fascismo na sociedade italiana, e sendo assim, era inadmissível para ele que a luta contra o fascismo se resumisse apenas à derrota de Mussolini e na restauração da falsa democracia em que o país se encontrava antes.

Ainda na quarta parte do livro, encontramos um subcapítulo sobre o período em que Chiaromonte, impulsionado pelos pensamentos revolucionários que o levaram à ruptura com o grupo reformista de Rosselli, foi combater na Guerra Civil Espanhola ao lado do escritor francês André Malraux. Panizza nos conta que essa experiência de combate foi importante para o desenvolvimento de uma característica central do pensamento chiaromontiano, ou seja, a coerência entre pensamento e ação. Chiaromonte viu nas manifestações populares de Madrid a mais espontânea luta pela liberdade de um povo, desligada de qualquer ideologia política preestabelecida, que não a liberdade.

O breve capítulo V, "Intermezzo. Mediterraneo" (p.163-171), discorre sobre a fuga de Chiaromonte da Europa, motivado pelo mandado de prisão por propaganda antifascista na Itália e pela recém invasão hitleriana da capital francesa. Seu objetivo era de embarcar para os Estados Unidos, porém tendo os principais portos europeus sido restritos, teve de tomar um itinerário pelo norte da África até a Argélia, onde conseguiu embarcar. O período de alguns meses na Argélia foi muito marcante para o crítico italiano, porque ali entrou em contato com o ainda jovem Albert Camus. Apesar do curto período em que estiveram em contato, Chiaromonte e o escritor francês tiveram uma profunda identificação de pensamento, que se transformaria em uma amizade duradora. Camus e sua mulher estavam refugiados ali, mas não pretendiam viajar para os Estados Unidos. 
Os anos de verdadeiro exílio na capital estadunidense são contados no sexto capítulo, "New York. Esule dall'Europa (1941-1948)" (p. 173-201), quando Chiaromonte esteve pela primeira vez em um ambiente totalmente diferente do Europeu, onde a divergência cultural, moral e filosófica o fez sentir realmente como um exilado, já que em Paris se sentia culturalmente à vontade. Foram anos muito importantes para o aprofundamento da sua crítica à situação de massa, do mecanicismo, da corrupção dos gostos provocados pela cultura televisiva, da burocratização e desumanização do indivíduo.

Nova York era também o refúgio e lar de muitos dos grandes intelectuais da segunda metade do século. Chiaromonte entrou em contato com diversos nomes do pensamento político e cultural que ali estavam, entre eles Hannah Arendt, Meyer Schapiro e George Orwell, com o qual trabalharia nas publicações da Politics. Reaproximou-se de alguns antifascistas refugiados, principalmente com o Gaetano Salvemini, deputado socialista italiano, ex-integrante do grupo GL que, perseguido por Mussolini, foi obrigado a deixar a Europa. Mas certamente o encontro mais decisivo desse período foi com o escritor e editor Dwight MacDonald. Esta amizade entre os dois críticos muito os enriqueceu intelectualmente, porque compartilhavam dos mesmos pensamentos sobre a situação da sociedade moderna, porém, cada um deles através de uma experiência de vida diferente.

A renomada revista Politics nasceu do encontro entre esses dois pensadores. Tendo MacDonald e Chiaromonte como diretores, a revista, que já contava com os leitores da Partisian review, ganhou grande prestígio entre os intelectuais americanos e os imigrantes. Pela primeira vez, o crítico italiano teve o reconhecimento de seus escritos e se tornou uma referência na crítica aos governos totalitaristas. Panizza aponta como esse sucesso na metrópole americana explica o fato de Chiaromonte ser mais lembrado no exterior do que em seu próprio país, até os dias de hoje.

O sétimo capítulo é o terceiro dedicado à Paris, "Parigi III. Il ritorno nell'Europa della guerra fredda (1947-1953) (p. 203-232), e trata dos anos que sucederam a queda de Mussolini e o fim da Segunda Guerra Mundial. Apesar da vontade intrínseca de todo exilado de retornar à sua terra, a volta de Chiaromonte teve um objetivo intelectual de extrema importância para ele, o estabelecimento de uma rede de ligação entre os críticos de esquerda anti-stalinistas europeus e os colaboradores da Politics. A figura principal desse período é Camus, um dos poucos intelectuais europeus de renome que não era ligado aos ideais do comunismo. Em 1950, adere ao Congresso pela liberdade de cultura (CCF), grupo de intelectuais anticomunistas, que posteriormente revelou-se ser financiado pela CIA, mas onde conheceu muitos intelectuais renomados do cenário europeu como o compositor russo Nicolas Nabokov.

No capítulo VIII, "Roma II. In difesa del Tempo presente (1953-1966)" (p. 233-286), Panizza discorre sobre o retorno do crítico à capital italiana e a fundação do maior projeto intelectual de Chiaromonte, a revista Tempo Presente: Informazione e Discussione. Idealizada e dirigida junto com o romancista e ensaísta Ignazio Silone, de quem se aproximara por compartilhar a mesma visão antidogmática da sociedade e a busca perene em entender a verdade sobre 
a política e os caminhos da humanidade. A revista concebida sem nenhum vínculo com partido ou ideologia política limitante, era vista como publicação anticomunista, porque publicava textos de muitos exilados do leste europeu e lançava questionamentos e discussões inquietantes sobre o regime soviético, mas na verdade, Tempo Presente era um espaço de informação sobre os acontecimentos então atuais e de discussão sobre política, filosofia, cultura, literatura, teatro, enfim, uma revista de vasta abrangência ideológica e de variedade de conteúdos.

Panizza não se aprofunda muito no período e nas discussões propostas pela revista e por Chiaromonte. Seguindo o caminho de análise proposto pelo historiador nos outros capítulos, a relevância da questão política e a crítica que Chiaromonte faz dela é o que foi explorado nessa parte. A explicação se encontra na proposta do livro, que é de retratar mais o período de exílio que o trabalho na Itália, visto que o período italiano já foi alvo de outros estudos. Por fim, no capítulo IX, “Epilogo. "la grotta di Paros (1966-1972)” (p.287-314) Panizza discorre sobre a crise e o fim da revista Tempo Presente, devido a fatores internos de divergência entre Chiaromonte e Silone, e externos, como a então recém descoberta dos financiamentos da CCF pela CIA.

A pesquisa histórico-biográfica feita por Panizza é uma contribuição muito rica para os estudos sobre Nicola Chiaromonte, um crítico quase silenciado na Itália, mas que vem aos poucos sendo resgatado por trazer uma visão sensível, ampla e problemática do século XX e dos governos totalitários. Panizza consegue mostrar como Chiaromonte sempre esteve na contracorrente do pensamento dominante, foi antifascista em uma Itália fascista, foi revolucionário em meio aos reformistas da GL, foi anticomunista em meio aos intelectuais comunistas americanos. Sempre contrário aos saberes dogmáticos, que excluem qualquer possiblidade de dúvida, sejam eles religiosos, políticos ou filosóficos. Em suma, um intelectual unicamente comprometido com a verdade e com a coerência entre pensamento intelectual e vida pessoal. 